\title{
Fluorescent Nanoparticle-Based Indirect Immunofluorescence Microscopy for Detection of Mycobacterium tuberculosis
}

\author{
Dilan Qin, ${ }^{1,2}$ Xiaoxiao He, ${ }^{1,2}$ Kemin Wang, ${ }^{1,2}$ Xiaojun Julia Zhao, ${ }^{3}$ Weihong Tan, ${ }^{1,2}$ and Jiyun Chen ${ }^{1,2}$ \\ ${ }^{1}$ State Key Laboratory of Chemo/Biosensing and Chemometrics, Biomedical Engineering Center, \\ College of Chemistry and Chemical Engineering, Hunan University, Changsha, Hunan 410082, China \\ ${ }^{2}$ Key Laboratory for Bio-Nanotechnology and Molecule Engineering of Hunan Province, Hunan University, Changsha 410082, China \\ ${ }^{3}$ Department of Chemistry, University of North Dakota, Grand Forks, ND 58202, USA \\ Correspondence should be addressed to Kemin Wang, kmwang@hnu.cn
}

Received 24 March 2007; Revised 10 July 2007; Accepted 10 October 2007

Recommended by Marek Osinski

A method of fluorescent nanoparticle-based indirect immunofluorescence microscopy (FNP-IIFM) was developed for the rapid detection of Mycobacterium tuberculosis. An anti-Mycobacterium tuberculosis antibody was used as primary antibody to recognize Mycobacterium tuberculosis, and then an antibody binding protein (Protein A) labeled with Tris(2,2bipyridyl)dichlororuthenium(II) hexahydrate (RuBpy)-doped silica nanoparticles was used to generate fluorescent signal for microscopic examination. Prior to the detection, Protein A was immobilized on RuBpy-doped silica nanoparticles with a coverage of $\sim 5.1 \times 10^{2}$ molecules/nanoparticle. With this method, Mycobacterium tuberculosis in bacterial mixture as well as in spiked sputum was detected. The use of the fluorescent nanoparticles reveals amplified signal intensity and higher photostability than the direct use of conventional fluorescent dye as label. Our preliminary studies have demonstrated the potential application of the FNP-IIFM method for rapid detection of Mycobacterium tuberculosis in clinical samples.

Copyright () 2007 Dilan Qin et al. This is an open access article distributed under the Creative Commons Attribution License, which permits unrestricted use, distribution, and reproduction in any medium, provided the original work is properly cited.

\section{INTRODUCTION}

Tuberculosis (TB) is a global public health emergency, fueled by the spread of human immunodeficiency virus (HIV)/Acquired Immune Deficiency Syndrome (AIDS) and the emergence of drug-resistant stains of Mycobacterium tuberculosis (M. tuberculosis). Approximately 2 billion peopleone third of the human population-are currently infected with $\mathrm{TB}$, with one new infection occurring every second. Each year there are more than 8.8 million cases and close to 2 million deaths attributed to TB worldwide. Experts at the World Health Organization (WHO) predicted these numbers would escalate in coming decades, nearly 1 billion people would become newly infected, over 150 million would become sick, and 36 million would die worldwide between now and 2020-if control was not further strengthened [1]. Rapid and accurate diagnosis of tuberculosis is a critical step in the management and control of TB. For decades, diagnosis has largely relied on acid-fast staining and culture of bacilli. However, the sensitivity of acid-fast staining is poor, and culture is a relatively time-consuming process. Many ef- forts have been directed toward developing techniques for rapid diagnosis of tuberculosis with higher sensitivity and reliability [2], including methods based on molecular biology (molecular diagnosis techniques) [3], such as nucleic acid amplification tests (NAA tests) [4, 5], DNA probes [6,7]; and methods based on immunology (serodiagnosis techniques) [8], such as enzyme-linked immunosorbent assay (ELISA) $[9,10]$, immunochromatographic assay [11], latex agglutination assay [12]. Recently, more simple, direct, and visually detectable assays have been developed for rapid diagnosis of TB with Au nanoparticles [13, 14]. These approaches have contributed much on the improvement of sensitivity and accuracy of the detection but still exhibit deficiencies in some extent [15]. NAA tests have been the subject of a number of investigations. Many commercial kits are available including the Amplicor and MTD tests which are currently US FDA approved. The NAA tests have high specificity and work better to rule-in TB. However, sensitivity of NAA tests is lower and it is less good to rule-out TB. Serological tests for the diagnosis of tuberculosis have been attempted for decades. Dozens of commercial kits are available, most of which are focused 
on antibody detection. However, assays based on antibodies detection are hard to distinguish active TB from BCG vaccination and past infection. Therefore, more studies are needed to develop and improve the detection methods for tuberculosis.

Dye-doped silica nanoparticles [16, 17], exhibiting such important advantages as high luminescence and photostability compared to conventional fluorescent dyes, have been widely applied in biological imaging and ultrasensitive bioanalyses, including cell staining [18], DNA detection [19, 20], cell surface receptor targeting [21-24], and ultrasensitive detection of Escherichia coli O157:H7 [25]. Owing to the dye-encapsulated structure, thousands of dye molecules embedded in one nanoparticle contribute to the luminescence of one particle, causing significant signal amplification. In this paper, we establish a rapid immunological method for detection of $M$. tuberculosis by combining highly luminescent RuBpy-doped nanoparticles with indirect immunofluorescence microscopy. Since direct anchoring of antibodies onto solid supports via covalence methods is always faced with the loss of activity of the antibodies, Protein A was applied as an affinitive adsorber. In order to obtain full antibody activity, M. tuberculosis was first recognized with the specific antibody in solution then signaled by Protein A functionalized fluorescent nanoparticles. This method was used to detect $M$. tuberculosis in mixed bacterial samples and spiked sputum samples. Meanwhile, signal intensity and photostability of the method were compared with conventional fluorescent dye fluorescein isothiocyanate labeling method.

\section{MATERIALS AND METHODS}

\subsection{Bacteria}

The H37Ra strain of M. tuberculosis was obtained from the National Institute for the Control of Pharmaceutical and Biological Products (Beijing, China). M. tuberculosis was cultured by Dr. Songlin Yi (Hunan Tuberculosis Hospital, Hunan, China) on modified Lowenstein-Jenson medium at $37^{\circ} \mathrm{C}$ for 3-4 weeks to obtain pure bacterial culture for use in establishing detection method. M. tuberculosis was harvested in $\mathrm{pH} 7.4,0.01 \mathrm{M}$ phosphate buffered saline (PBS) to form predominantly single-cell suspension using previously described method [26]. E. coli strain DH5 $\alpha$ (Microbial Culture Collection Center of Guangdong Institute of Microbiology, Guangdong, China) was grown overnight in Luria-Bertani broth at $37^{\circ} \mathrm{C}$. The bacterial suspensions were counted in a Petroff-Hausser chamber, and the concentrations of bacteria were adjusted for use in experiments.

\subsection{Materials}

Tris(2,2-bipyridyl)dichlororuthenium(II) hexahydrate (RuBpy), Triton X-100, fluorescein isothiocyanate (FITC), and Protein A from Staphylococcus aureus were purchased from Sigma-Aldrich. Sodium carbonate, sodium bicar- bonate, sodium dihydrogen phosphate, disodium hydrogen phosphate, sodium hydroxide, sodium citrate, acetonitrile, glycine, and N-acetyl-L-cysteine (NALC) of analytical grade were obtained from China National Medicines Group Shanghai Chemical Reagents Company (Shanghai, China). Cyanogen Bromide $(\mathrm{CNBr})$ was synthesized using previously described method [27]. Purified rabbit anti-M. tuberculosis IgG and FITC-conjugated rabbit anti-M. tuberculosis IgG were supplied by Biodesign International (Me, USA). Rabbit anti-p53 IgG was purchased from Boster Biological Technology (Wuhan, China).

\subsection{Instrumentation}

The morphology and uniformity of RuBpy-doped silica nanoparticles were measured with an atomic force microscope (AFM) SPI3800N-SPA400 (Seiko). Size distribution analysis of RuBpy-doped silica nanoparticles was determined at $25^{\circ} \mathrm{C}$ by dynamic light scattering (DLS) using Zetasizer $3000 \mathrm{HS}_{\mathrm{A}}$ (Malvern). The volume-weighted average diameter obtained by the manufacturer's software was used for the calculation of the average nanoparticle volume. A refractive index of 1.47 was used for nanoparticles (the refractive index of silica). Viscosity was determined at $30^{\circ} \mathrm{C}$ using a cone plate digital viscometer LVDV-III+CP (Brookfield). Determination of protein concentration according to the Bradford method was done with a UV-Vis spectrophotometer DU-800 (Beckman) [28].

\subsection{Biological modification of the RuBpy-doped silica nanoparticles}

RuBpy-doped silica nanoparticles were prepared using the water-in-oil (W/O) microemulsion method that had been described before [21]. In order to immobilize Protein A onto the nanoparticles, the surface of the RuBpy-doped silica nanoparticles was first activated with $\mathrm{CNBr}$. Nanoparticles $(11.2 \mathrm{mg}$ ) were suspended in $2 \mathrm{ml}$ of $2 \mathrm{M}$ sodium carbonate solution by ultrasonication. A solution of $\mathrm{CNBr}$ in acetonitrile ( $0.78 \mathrm{~g}$ of $\mathrm{CNBr}$ dissolved in $2 \mathrm{ml}$ of acetonitrile) was then added dropwise to the particle suspension under stirring at room temperature for 5 minutes. After the activation reaction, the particles were washed twice with ice-cold water and twice with pH 7.4, 0.01 M PBS buffer. For covalently coupling of Protein A onto the nanoparticle surface, a $40 \mu \mathrm{l}$ portion of aqueous solution of $2 \mathrm{mg} / \mathrm{ml}$ Protein A was added to $1 \mathrm{ml}$ of $1.1 \mathrm{mg} / \mathrm{ml}$ freshly activated nanoparticles in PBS, and stirring was continued for 24 hours at $4^{\circ} \mathrm{C}$. The Protein A immobilized nanoparticles were then blocked with $6 \mathrm{ml}$ of $0.3 \mathrm{M}$ glycine solution ( $\mathrm{pH} 8.0$ ) $4^{\circ} \mathrm{C}$ for 16 hours in order to reduce the effect of nonspecific binding in the subsequent immunoassay. The final product was washed, resuspended in PBS, and stored at $4^{\circ} \mathrm{C}$ for future usage. The surface coverage of Protein A on nanoparticles was determined by measuring the decrease of Protein A concentration in the coupling solution by the Bradford method $[28,29]$. 


\subsection{Indirect immunofluorescence detection of M. tuberculosis with bioconjugated nanoparticles}

Rabbit anti-M. tuberculosis antibody was added to a $500 \mu \mathrm{l}$ suspension of $M$. tuberculosis in PBS (antibody final concentration: $5 \mu \mathrm{g} / \mathrm{ml}$ ) and incubated at $37^{\circ} \mathrm{C}$ for 1 hour. The suspension was subsequently washed with PBS twice. Nanoparticle-Protein A conjugates $(0.1 \mathrm{mg} / \mathrm{ml})$ were then added, and the mixture was incubated at $37^{\circ} \mathrm{C}$ for 1 hour. To remove the free nanoparticle-Protein A conjugates that did not bind to the bacteria, the mixture was centrifuged at $8000 \mathrm{rpm}$ for 2 minutes, and then the supernatant was discard. The pellet was washed twice again. Smear slide was made by spreading the pellet on glass slide and observed with fluorescence microscopy or confocal microscopy. For controls, the rabbit anti-p53 antibody or PBS only was substituted for the primary antibody. Another bacterium E. coli $\mathrm{DH} 5 \alpha$ was treated with the same strategy to test the crossreaction with bioconjugated nanoparticles.

For immunofluorescence detection of M. tuberculosis with FITC-labeled antibody, the FITC-conjugated rabbit anti-M. tuberculosis antibody was added to a $500 \mu \mathrm{l}$ suspension of $M$. tuberculosis in PBS (antibody final concentration: $25 \mu \mathrm{g} / \mathrm{ml}$ ) and the mixture was incubated at $37^{\circ} \mathrm{C}$ for 1 hour. The suspension was subsequently washed with PBS for three times and then spread on glass slide for microscopic examination.

\subsection{Preparation of mixed bacterial sample}

The mixed bacterial sample was prepared by mixing FITClabeled E. coli and unlabeled M. tuberculosis. The FITClabeled E. coli was first obtained according to the following method. E. coli was incubated at a concentration of $10^{9}$ cells $/ \mathrm{ml}$ with $0.5 \mathrm{mg}$ of FITC in $0.1 \mathrm{M} \mathrm{Na}_{2} \mathrm{CO}_{3}-\mathrm{NaHCO}_{3}$ buffer ( $\mathrm{pH} \mathrm{9.2)} \mathrm{at} 37^{\circ} \mathrm{C}$ for 2 hours in the dark. The E. coli was then washed for three times with PBS to remove free FITC and resuspended in PBS. A $500 \mu \mathrm{l}$ of mixed bacterial sample was prepared by easily mixing $1.8 \times 10^{6} \mathrm{cells} / \mathrm{ml}$ FITClabeled E. coli and $3.6 \times 10^{5}$ cells $/ \mathrm{ml}$ unlabeled M. tuberculosis. The mixture was detected with the FNP-IIFM method.

\subsection{Preparation of spiked sputum sample}

Sputum $(2 \mathrm{ml})$ from healthy individual was collected and equally divided into two portions. One portion was spiked with M. tuberculosis, whereas the other portion was used as the unspiked sample. Then samples were liquefied with the NALC- $\mathrm{NaOH}$ method. In brief, the samples were mixed with equal volumes of NALC- $\mathrm{NaOH}$ solution $(2 \% \mathrm{NaOH}, 1.45 \%$ Na-citrate, and $0.5 \%$ NALC), shaken vigorously for digestion, and the mixtures were allowed to stand for 15 minutes at room temperature. Then the samples were diluted with $8 \mathrm{ml}$ of water. To remove big agglomerates in the sputum, the mixtures were centrifuged at $1000 \mathrm{rpm}$ for 2 minutes. The precipitates were disposed and the supernatants were centrifuged at $4000 \mathrm{~g}$ for 15 minutes. After the supernatant fluids were carefully decanted, the sediments were resuspended in
$10 \mathrm{ml}$ of PBS and centrifuged again at $4000 \mathrm{~g}$ for 15 minutes. The supernatants were discarded. The resulting pellets were suspended in $500 \mu \mathrm{l}$ of PBS and detected with the FNP-IIFM method.

\subsection{Microscopy imaging}

An inverted fluorescence microscope ECLIPSE TE300 (Nikon) equipped with a $100 \mathrm{~W}$ mercury lamp, a filter block (consisting of a $450-490 \mathrm{~nm}$ bandpass excitation and a $515 \mathrm{~nm}$ longpass emission filter), and a color CCD (Digital Camera DXM1200, Nikon) was used for common smear microscopic examination. Confocal microscopy was performed on an inverted Olympus IX70 microscope with an argon/krypton laser emitting at $488 \mathrm{~nm}$ to excite both RuBpy-doped nanoparticles and FITC fluorescence. We used a dichroic beam splitter (DCB) around $560 \mathrm{~nm}$, together with either a longpass (LP) $560 \mathrm{~nm}$ filter for RuBpy-doped nanoparticles signal or an LP $505 \mathrm{~nm}$ filter for FITC signal. The RuBpy-doped nanoparticles signal was displayed in the pseudocolor red and the FITC signal in green. To study the differentiation between $M$. $t u$ berculosis and $E$. coli in mixed bacterial samples with the FNP-IIFM method, the smears were scanned by sequential excitation mode. In brief, an argon/krypton laser emitting at $488 \mathrm{~nm}$ and a helium/neon laser emitting at $543 \mathrm{~nm}$ were used to excite FITC and RuBpy-doped silica nanoparticles fluorescence, respectively. We used a DCB around $560 \mathrm{~nm}$, together with the following emission filter: either a bandpass (BP) $505-525 \mathrm{~nm}$ when the argon/krypton laser (FITC signal) was used or an LP $560 \mathrm{~nm}$ when the helium/neon laser (RuBpy-doped silica nanoparticles signal) was used. A $\times 60$ objective (Olympus PlanApo NA 1.4 oil) was used for routine studies. Pixel format was $512 \times$ 512 .

\section{RESULTS AND DISCUSSION}

\subsection{Highly luminescent and photostable fluorescent nanoparticles}

We used an easy and efficient water-in-oil microemulsion method to synthesize RuBpy-doped silica nanoparticles. The obtained nanoparticles were uniform and well dispersed as shown in the AFM image (Figure 1(a)). Dynamic light scattering (DLS) measurements for the nanoparticles showed that the size distribution of RuBpy-doped nanoparticles was narrow and the volume-weighted mean hydrodynamic diameter determined was $63.8 \mathrm{~nm}$ (Figure 1(b)). For the structure of dye-doped silica nanoparticles, dye molecules are trapped inside the silica matrix, which endows the nanoparticles with two important merits. For one thing, the fluorescence emitted by one nanoparticle is contributed by thousands of dye molecules embedded in the silica matrix. So it is easy to see that one dye-doped nanoparticle is much more luminescent than one dye molecule, which is called the significant signal amplification effect. This attribute makes the dye-doped nanoparticles be advantageous 


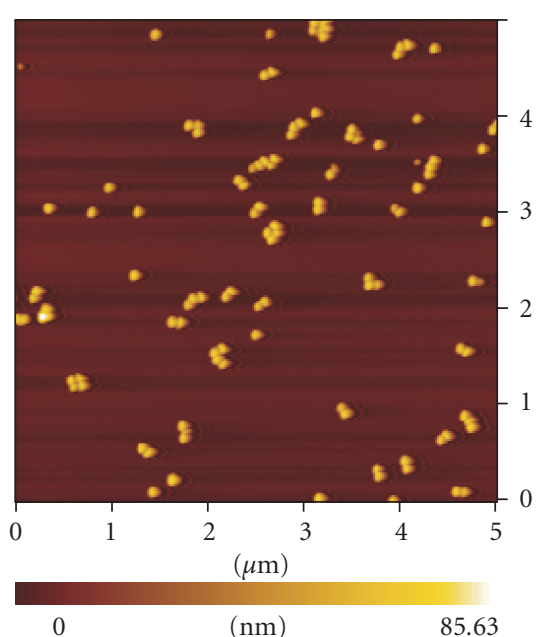

(a)

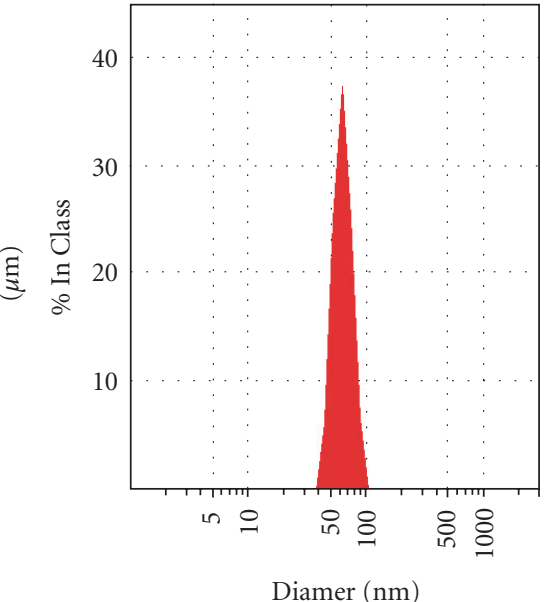

(b)

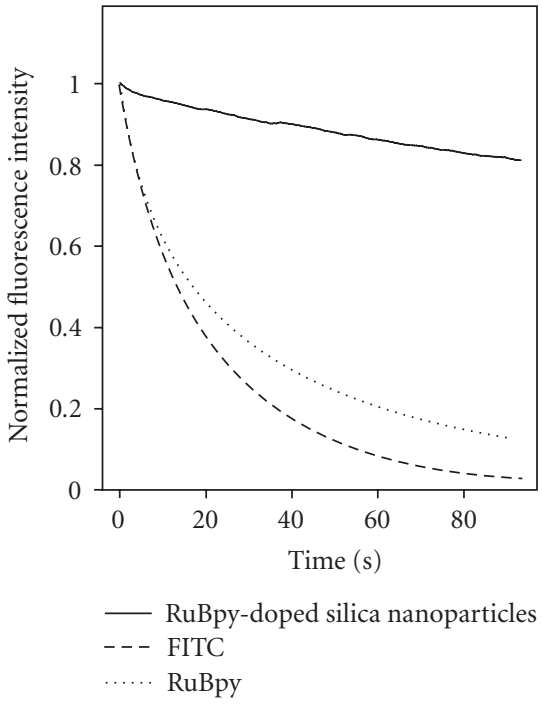

(c)

Figure 1: Properties of RuBpy-doped silica nanoparticles. (a) AFM micrograph of the RuBpy-doped silica nanoparticles. Particle size is determined to be $65 \pm 2 \mathrm{~nm}$. (b) Size distribution analysis of RuBpy-doped silica nanoparticles in water by dynamic light scattering (DLS). The volume-weighted average diameter determined is $63.8 \mathrm{~nm}$. (c) Photostability of RuBpy-doped silica nanoparticles versus pure RuBpy dye molecules and FITC dye molecules. Realtime measurements of fluorescence intensities were performed on an confocal microscope with an intensive argon/krypton laser as the excitaton source.

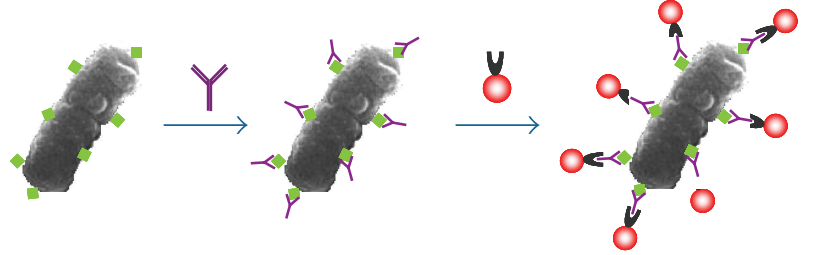

M. tuberculosis

- Surface antigen of M. tuberculosis

Y Protein A modified fluorescence Nanoparticles

Specific antibody

FIGURE 2: Schematic representation of the principle of the detection of $M$. tuberculosis with the fluorescent nanoparticle-based indirect immunofluorescence assay.

in improving detection sensitivity in many aspects and very suitable for detection of bacteria with higher sensitivity. As another advantage, due to the protective function of the silica matrix, the nanoparticles are much more photostable than ordinary dye molecules. As shown in Figure 1(c), after continuous intensive illumination with a laser source for 80 seconds, the fluorescence intensities of both RuBpy and FITC dyes were decreased to below $20 \%$, while the fluorescence intensiy of RuBpy-doped nanoparticles remained above $80 \%$.

\subsection{Covalent immobilization of Protein A on nanoparticles}

Covalent attachment of antibodies directly to solid supports via glutaraldehyde, carbodiimide, succinimide ester, and so forth is always found with the loss of biological activity of the antibodies. One of the main reasons for such reduction is attributed to the random orientation of the asymmetric macromolecules on support surface [30]. Several approaches for achieving oriented antibody coupling for good steric accessibilities of active binding sites and increased stability have been developed, including the use of Protein A or Protein G [31], chemical or enzymatic oxidation of the immunoglobulin (IgG) carbohydrate moiety [32], and the use of biotinavidin or streptavidin techniques [33]. Protein A, a highly stable $42 \mathrm{kDa}$ coat protein extracted from Staphylococcus aureus, is capable of binding to the Fc portion of immunoglobulins, especially IgGs, from a large number of species [34]. In our scheme, Protein A was used as an affinitive adsorber to avoid direct attachment of antibody to nanoparticles.

For immobilization of Protein A on the RuBpy-doped silica nanoparticles, the $\mathrm{CNBr}$ method was used to activate the surface of silica nanoparticles and then couple the Protein A. The surface coverage of Protein A on the nanoparticles was quantified by the Bradford method, and the average mass of one particle was determined through the viscosity/light scattering method, then the number of Protein A molecules attached to one particle could be calculated. The amount of Protein A immobilized on nanoparticles was calculated approximately as [29]:

$$
q=\left[\left(C_{i}-C_{t}\right) V\right] / m
$$




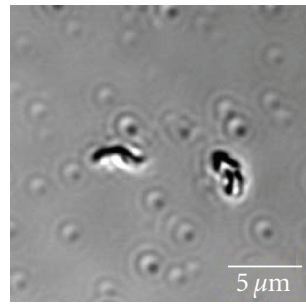

(a)

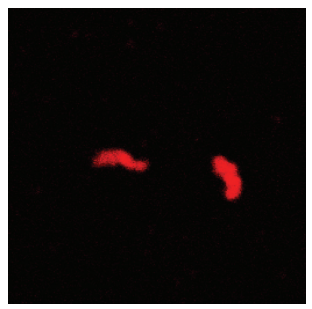

(f)

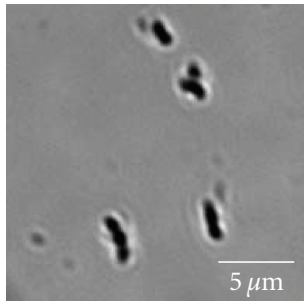

(b)

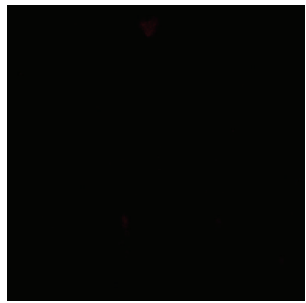

(g)

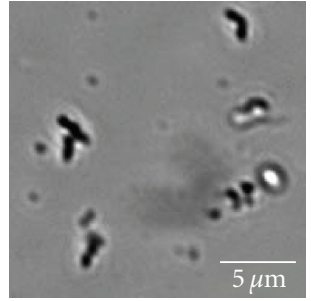

(c)

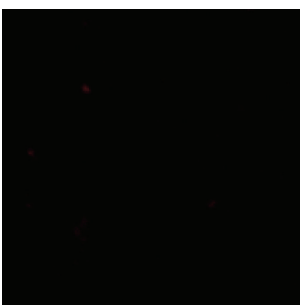

(h)

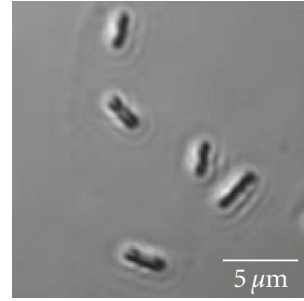

(d)

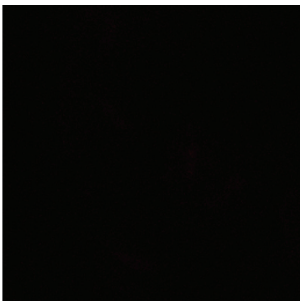

(i)

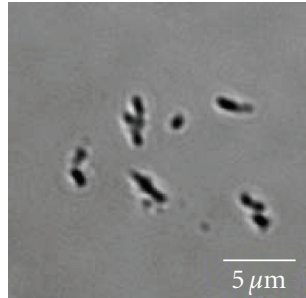

(e)

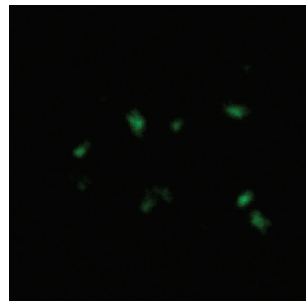

(j)

Figure 3: The specific, nonspecific interactions, and signal amplification effect of biocojugated nanoparticles interacted with bacteria. All pictures were obtained with confocal microscopy $(60 \times$ oil), (a)-(e) transmission images, (f)-(j) fluorescence images. (a), (f) M. tuberculosis recognized with bioconjugated fluorescent nanoparticles. The bacteria display a bright fluorescence. (b), (g) Control with PBS in place of the primary rabbit anti-M. tuberculosis antibody. No fluorescence is associated with the bacteria. (c), (h) Control with rabbit anti-p53 antibody in place of the primary rabbit anti-M. tuberculosis antibody. No fluorescence is associated with the bacteria. (d), (i) E. coli incubated with bioconjugated fluorescent nanoparticles. No labeling of the bacteria with nanoparticle bioconjugates is observed. (e), (j) M. tuberculosis recognized with FITC conjugated rabbit anti-M. tuberculosis antibody. The bacteria display a faint fluorescence.

where $q$ is the amount of Protein A immobilized onto a unit mass of the nanoparticles $(\mathrm{mg} / \mathrm{mg}) ; C_{i}$ and $C_{t}$ are the concentrations of the Protein $A$ in the initial solution and in the supernatant after the immobilization reaction, respectively $(\mathrm{mg} / \mathrm{ml}) ; V$ is the volume of the aqueous phase $(\mathrm{ml})$; and $m$ is the mass of the nanoparticles (mg). $C_{i}$ and $C_{t}$ were determined by the Bradford method [28]. The amount of Protein A immobilized on nanoparticles calculated according to (1) in our experiment was $\sim 0.41 \mathrm{mg} / \mathrm{mg}$. The average mass of one particle was then determined and calculated as

$$
m_{i}=C / N
$$

where $m_{i}$ is the average mass of one nanoparticle $(\mathrm{mg}) ; C$ is the concentration of the nanoparticle suspension $(\mathrm{mg} / \mathrm{ml})$; $N$ is the number of nanoparticles in a unit volume of suspension liquid (particles/ml), which was calculated through the viscosity/light scattering method [35] as

$$
N=\phi /\left[4 / 3 \pi(d / 2)^{3}\right]
$$

where $4 / 3 \pi(d / 2)^{3}$ is the average volume of a nanoparticle; $d$ is the volume-weighted diameter determined by light scattering; and $\phi$ is the volume fraction of the particles determined by viscosity and calculated as

$$
\phi=\left(h / h_{0}-1\right) / 2.5
$$

where $h$ is the viscosity of the nanoparticle suspension; $h_{0}$ is the viscosity of the solvent without nanoparticles. According to (2)-(4), the average mass of one nanoparticle calculated was $\sim 8.8 \times 10^{-17} \mathrm{~g}$. So there were $\sim 3.6 \times 10^{-14} \mathrm{mg}$ Protein A on one particle, that is, $\sim 5.2 \times 10^{2}$ Protein A molecules on one particle. It provided a foundation for optimal binding of the nanoparticle-Protein A conjugates with the antibody in the later process.

\subsection{Detection of M. tuberculosis in pure culture}

A method of fluorescent nanoparticle-based indirect immunofluorescence microscopy (FNP-IIFM) was developed for the rapid detection of Mycobacterium tuberculosis. The principle for this method was illustrated in Figure 2. In this scheme, $M$. tuberculosis was first recognized by a rabbit antiM. tuberculosis antibody and then the nanoparticle-Protein A conjugates were used to generate fluorescent signal. To examine the binding of bioconjugated nanoparticles to bacteria, the incubated bacteria were imaged using either fluorescence microscopy or confocal microscopy.

Pure M. tuberculosis suspension was first immunodetected with the FNP-IIFM method and the resulting confocal images were shown in Figures 3(a), 3(f). The bacteria displayed a bright fluorescence. This indicated that large quantities of nanoparticles had bound to the M. tuberculosis cells. In order to demonstrate whether the binding of bioconjugated nanoparticles to M. tuberculosis was solely through the antigen-specific targeting pattern or there were other nonspecific interactions between the Protein A-nanoparticle conjugates and other surface molecules of the bacteria, two controls were set in which the primary antibody was substituted with the following: (1) PBS only; (2) a rabbit anti-p53 


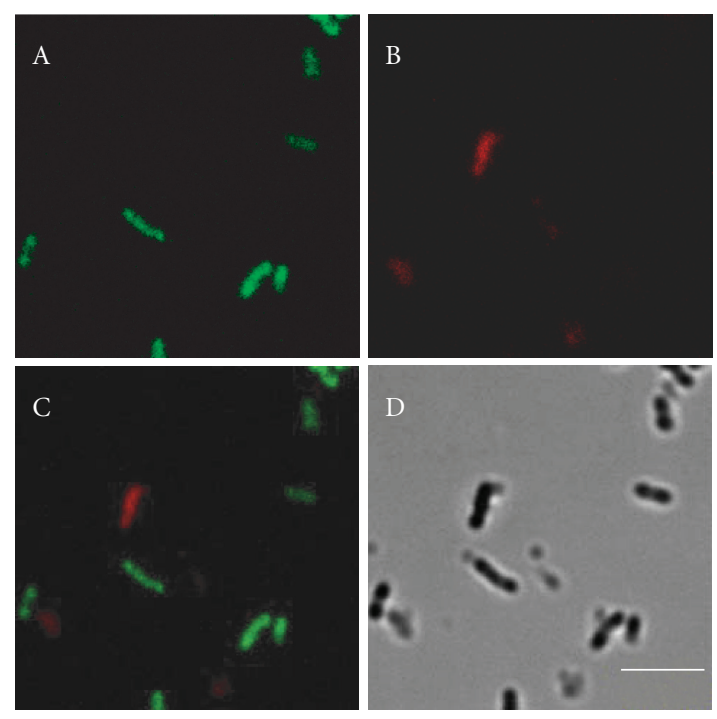

(a)

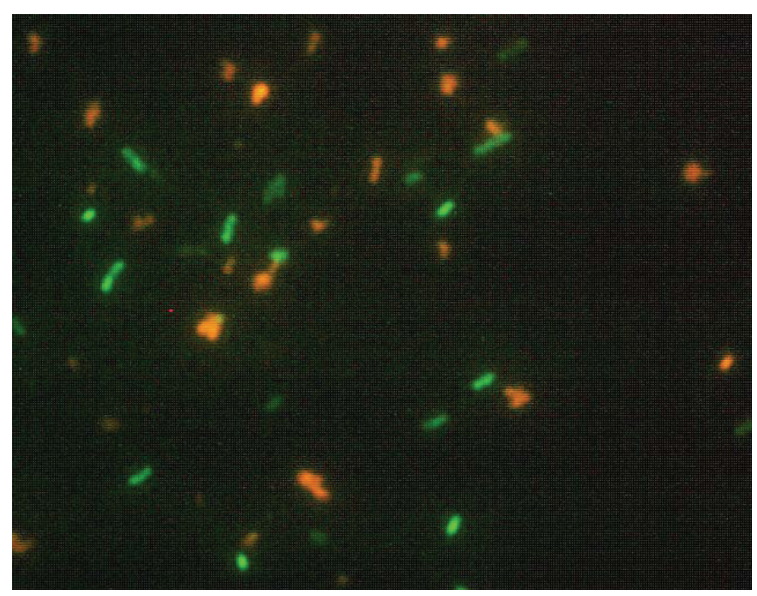

(b)

FIgURE 4: Detection of $M$. tuberculosis in mixed bacterial samples with the FNP-IIFM method. A mixture containing $1.8 \times 10^{6} \mathrm{cells} / \mathrm{ml}$ FITC-labeled E. coli and $3.6 \times 10^{5}$ cells/ml unlabeled M. tuberculosis was detected. (a) Confocal microscopic images $(60 \times$ oil $):(A) \mathrm{im}-$ age obtained after excitation with the $488 \mathrm{~nm}$ laser and displayed in the pseudocolor green (FITC signal); (B) image obtained after excitation with the $543 \mathrm{~nm}$ laser and displayed in the pseudocolor red (RuBpy-doped nanoparticles signal); (C) overlay of the green channel and the red channel images; (D) transmission image. The confocal images show that there is no colocalization of the red fluorescent nanoparticles with E. coli (green). (b) Truecolor fluorescence image $(100 \times$ oil $)$ with an inverted fluorescence microscope. Green: FITC-labeled E. coli; Orange: bioconjugated fluorescent nanoparticles identified $M$. tuberculosis. The differentiation of $M$. tuberculosis from E. coli in the mixture with the FNP-IIFM method is good.

antibody. No fluorescence was observed to associate with the M. tuberculosis in both controls as shown in Figures 3(b), $3(\mathrm{~g})$ and $3(\mathrm{c}), 3(\mathrm{~h})$, suggesting that there was little nonspecific interaction between the Protein A-nanoparticle conjugates and the M. tuberculosis cell wall. These results identify that the bioconjugated nanoparticles bind to M. tuberculosis through the antibody-mediated antigen binding pattern. Another bacterium E. coli DH5 $\alpha$ was also tested with the FNPIIFM method. No labeling of the bacteria with the nanoparticle bioconjugates was observed as shown in Figures 3(d), $3(i)$. The result shows that the anti-M. tuberculosis antibody does not cross-react with $E$. coli DH5 $\alpha$, and the nanoparticle bioconjugates do not attach to $E$. coli $\mathrm{DH} 5 \alpha$ nonspecifically, which indicates that the FNP-IIFM method can be used to detect Mycobacterium tuberculosis in pure culture.

The fluorescence enhancement capability of the bioconjugated nanoparticles label in the FNP-IIFM method has also been investigated. The detection of M. tuberculosis with bioconjugated RuBpy-doped nanoparticles was compared with the commercial FITC conjugated rabbit anti-M. tuberculosis antibody. The final antibody concentration used in the FITC method was $25 \mu \mathrm{g} / \mathrm{ml}$. It was 5-fold higher than that used in the FNP-IIFM method. We used higher concentration of antibody in the FITC method because the induced fluorescence signal was too low when the antibody concentration was $5 \mu \mathrm{g} / \mathrm{ml}$. Figures $3(\mathrm{e}), 3(\mathrm{j})$ showed the confocal images of $M$. tuberculosis recognized by the FITC method. The fluorescence signal from the bacteria recognized with the FITC method (Figure 3(j)) was much weaker than the signal with the FNP-IIFM method (Figure 3(f)). Although the primary antibody used in the FNP-IIFM method was only one fifth of that used in the FITC method, the average fluorescence intensity of $M$. tuberculosis recognized with the FNP-IIFM method was determined to be above five times of that with the FITC method. The experiment reveals the signal advantage that the fluorescent nanoparticles possess over conventional fluorescent dye.

\subsection{Detection of M. tuberculosis in mixed bacterial samples}

To evaluate the detection capability of the FNP-IIFM method in complex samples, artificial complex samples consisting of M. tuberculosis and E. coli were used for test. In order to estimate the accuracy of the detection with the FNP-IIFM method in bacterial mixture, E. coli was labeled with FITC to distinguish from $M$. tuberculosis prior to the detection. Then the FITC-labeled E. coli was mixed with unlabeled $M$. tuberculosis to constitute the mixed bacterial samples and detected with the FNP-IIFM method. The results obtained with confocal microscopy were shown in Figure 4(a). The image in Figure 4(a)-A showed the FITC fluorescence associated with $E$. coli in the mixture (pseudocolor green, emission filter: BP 505-525 nm). Figure 4(a)-B showed the fluorescence of the bioconjugated RuBpy-doped nanoparticles which had bound to bacteria (pseudocolor red, emission filter: LP $560 \mathrm{~nm}$ ). If the nanoparticles also attached to E. coli, the fluorescence would appear yellow in the overlay image (the combination of green plus red). The overlay image in Figure 4(a)-C showed no colocalization of the red fluorescent nanoparticles with $E$. coli, so the bioconjugated nanoparticles only bound to the M. tuberculosis. Besides, the detection was also observed with the less-expensive fluorescence microscopy. As shown in Figure 4(b), the differentiation of M. tuberculosis from E. coli with the FNP-IIFM method was 


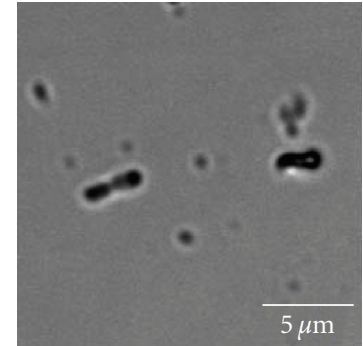

(a)

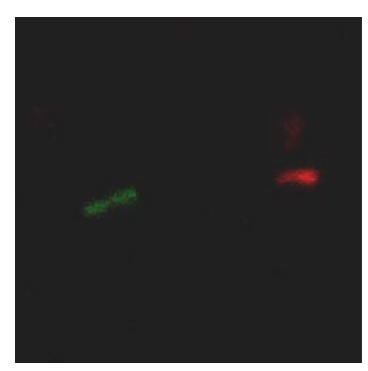

(d)

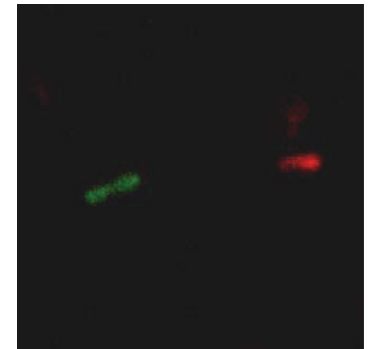

(b)

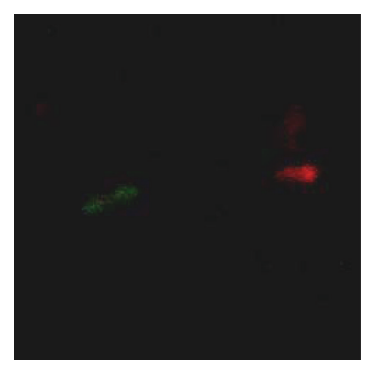

(e)

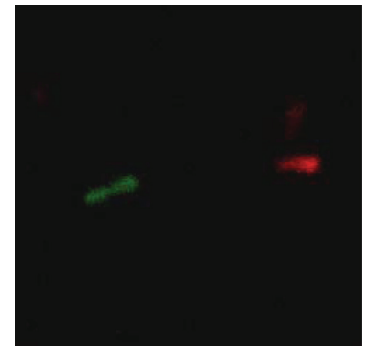

(c)

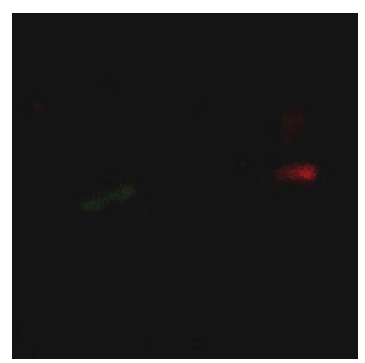

(f)

Figure 5: Photostability comparing of the fluorescent nanoparticles labeled on M. tuberculosis and FITC dyes labeled on E. coli. A mixture containing $1.8 \times 10^{6}$ cells $/ \mathrm{ml}$ FITC-labeled $E$. coli and $3.6 \times 10^{5}$ cells $/ \mathrm{ml}$ unlabeled M. tuberculosis was detected with the FNP-IIFM method. The slide was successive irradiated with an intensive argon/krypton laser under the confocal microscope (60 × oil) for (a) and (b) 0 second, (c) 1 minute, (d) 2 minutes, (e) 4 minutes, (f) 6 minutes. (a) Transmission image, (b)-(f) Fluorescence images. Green: E. coli; Red: M. tuberculosis. The fluorescence of FITC was dim after being continuously irradiated for 2 minutes while that of the nanoparticles was still bright.

good. These results indicate that the FNP-IIFM method can be used to detect $M$. tuberculosis in mixed bacterial samples.

Meanwhile, the photostability of the fluorescent label in the FNP-IIFM method was also investigated. We compared the photostability of RuBpy-doped nanoparticles bound on M. tuberculosis and FITC dyes labeled on E. coli. The fluorescence of FITC was dim after being continuously irradiated for 2 minutes while that of the nanoparticles was still bright, as shown in Figure 5. It is demonstrated that the bioconjugated RuBpy-doped silica nanoparticles used in the FNPIIFM method possess much better photostability in comparison with the FITC dye label.

\subsection{Detection of M. tuberculosis in spiked sputum}

In order to demonstrate the usefulness of our method for $M$. tuberculosis detection under clinical condition, M. tuberculosis was spiked into sputum and detected with the FNP-IIFM method. The result was compared with unspiked sputum control to make certain whether the M. tuberculosis could be detected in the sputum. Sputum from healthy individual was collected and equally divided into two portions. One portion was spiked with $M$. tuberculosis, whereas the other portion was used as the unspiked sample. The spiked sample and unspiked sample were parallelly pretreated and detected by the FNP-IIFM method. For sample pretreatment, we used the NALC-NaOH method to liquefy the sputum. After liquefaction for 15 minutes, the viscosity of the sputum was greatly decreased. However, there were some visible big agglomerates in both the spiked and unspiked sputum which could neither be liquefied nor be brokenup by vigorously vortexing. These big agglomerates caused poor smear quality such as uneven thickness, and had better been removed before immuno-reaction. To remove the big agglomerates, we centrifuged the liquefied sputum samples at low centrifugal speed (1000 rpm, 2 minutes) and disposed the precipitates. The supernatants were detected with the FNP-IIFM method. As we expected, the sputum samples were much complex mixtures containing a great deal of bacteria and impurities shown in Figure 6. In the unspiked sputum sample, no fluorescent bacterium was found as shown in Figure 6(b). It indicates that the bioconjugated nanoparticles have little nonspecific interaction with the sputum components and the oral bacteria. In the spiked sputum sample, we found highly luminescent bacteria in many microscopic fields as shown in Figure 6(a) (the luminescent bacterium indicated by the arrow). By comparing with the unspiked sample, the luminescent bacteria were considered to be $M$. tuberculosis recognized by the bioconjugated nanoparticles. The high intensity of fluorescence associated with the recognized M. tuberculosis well distinguished the object bacteria from the complex background. The time needed to finish detecting $M$. Tuberculosis with the FNP-IIFM method in sputum is $<4$ hours after the receipt of specimen (sample pretreatment: $<1$ hour, immunoassay and smear examination: $<3$ hours). This result demonstrates that our FNP-IIFM method is useful for rapid detection of M. tuberculosis in sputum. 


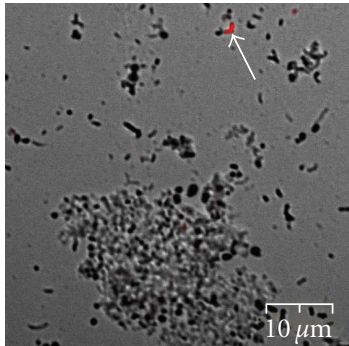

(a)

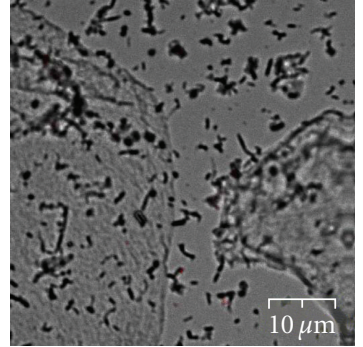

(b)
Figure 6: Detection of M. tuberculosis in spiked sputum. M. tuberculosis spiked sputum and unspiked sputum control were detected with the FNP-IIFM method after pretreatment with the NALC$\mathrm{NaOH}$ method. Both images were overlay of the fluorescence channel and the trasmitted channel of confocal images $(60 \times$ oil $)$. (a) Sputum spiked with M. tuberculosis. Note that a bacterium displays bright fluorescence, indicated by the arrow. (b) Unspiked sputum. No fluorescent bacterium is found.

\section{CONCLUSIONS}

We have developed a new method for the detection of $M$. $t u$ berculosis using fluorescent nanoparticle-based indirect immunofluorescence microscopy. With this method, $M$. tuberculosis can be detected in both mixed bacterial samples and sputum samples. Total assay time including sample pretreatment is within 4 hours. Comparing with conventional fluorescent dyes, the use of fluorescent nanoparticles as label in immunofluorescence microscopy offers advantages of higher luminescence and higher photostability. This method can integrate with epifluorescent filter techniques to further shorten the time needed for detection. In addition, by substituting the antibody to suit to other bacteria, this technique has the potential to develop to a universal method for detecting a wide variety of bacteria in biomedical and biotechnological areas.

\section{ACKNOWLEDGMENTS}

The authors thank Dr. Songlin Yi (Hunan Tuberculosis Hospital, Hunan, China) for his kind help on the culture of M. tuberculosis. This work was partially supported by the National Key Basic Research Program (2002CB513110), Key Technologies Research and Development Program (2003BA310A16), Key Project of Hunan Province Technology Plan of China (03SSY101), Hi-Tech Research and Development Program of China (863), Grant no. 2003AA302250, Key Project Foundation of China Education Ministry (107084), Program for New Century Excellent Talents in University (NCET-06-0697), National Science Foundation of China (90606003, 20405005), and Outstanding Youth Foundation of Hunan Province (06JJ10004).

\section{REFERENCES}

[1] World Health Organization. Global TB Control Report, 2003.

[2] J. C. Palomino, "Nonconventional and new methods in the diagnosis of tuberculosis: feasibility and applicability in the field," European Respiratory Journal, vol. 26, no. 2, pp. 339350, 2005.

[3] V. C. C. Cheng, W. W. Yew, and K. Y. Yuen, "Molecular diagnostics in tuberculosis," European Journal of Clinical Microbiology and Infectious Diseases, vol. 24, no. 11, pp. 711-720, 2005.

[4] B. I. Restrepo, D. I. Gomez, G. L. Shipley, J. B. McCormick, and S. P. Fisher-Hoch, "Selective enrichment and detection of mycobacterial DNA in paucibacillary specimens," Journal of Microbiological Methods, vol. 67, no. 2, pp. 220-229, 2006.

[5] Y. J. Yun, K. H. Lee, H. H. Lin, et al., "Detection and identification of Mycobacterium tuberculosis in joint biopsy specimens by rpoB PCR cloning and sequencing," Journal of Clinical Microbiology, vol. 43, no. 1, pp. 174-178, 2005.

[6] H. Park, H. Jang, E. Song, et al., "Detection and genotyping of Mycobacterium species from clinical isolates and specimens by oligonucleotide array," Journal of Clinical Microbiology, vol. 43, no. 4, pp. 1782-1788, 2005.

[7] S. Y. Lin, W. Probert, M. Lo, and E. Desmond, "Rapid detection of isoniazid and rifampin resistance mutations in Mycobacterium tuberculosis complex from cultures or smearpositive sputa by use of molecular beacons," Journal of Clinical Microbiology, vol. 42, no. 9, pp. 4204-4208, 2004.

[8] E. D. Chan, L. Heifets, and M. D. Iseman, "Immunologic diagnosis of tuberculosis: a review," Tubercle and Lung Disease, vol. 80, no. 3, pp. 131-140, 2000.

[9] T. Mustafa, H. G. Wiker, S. G. M. Mfinanga, O. Morkve, and L. Sviland, "Immunohistochemistry using a Mycobacterium tuberculosis complex specific antibody for improved diagnosis of tuberculous lymphadenitis," Modern Pathology, vol. 19, no. 12, pp. 1606-1614, 2006.

[10] L. M. Pereira Arias-Bouda, S. Kuijper, H. van Deutekom, et al., "Enzyme-linked immunosorbent assays using immune complexes for the diagnosis of tuberculosis," Journal of Immunological Methods, vol. 283, no. 1-2, pp. 115-124, 2003.

[11] C. Abe, K. Hirano, and T. Tomiyama, "Simple and rapid identification of the Mycobacterium tuberculosis complex by immunochromatographic assay using anti-MPB64 monoclonal antibodies," Journal of Clinical Microbiology, vol. 37, no. 11, pp. 3693-3697, 1999.

[12] S. Bhaskar, J. N. Banavaliker, K. Bhardwaj, and P. Upadhyay, "A novel ultrasound-enhanced latex agglutination test for the detection of antibodies against Mycobacterium tuberculosis in serum," Journal of Immunological Methods, vol. 262, no. 1-2, pp. 181-186, 2002.

[13] P. V. Baptista, M. Koziol-Montewka, J. Paluch-Oles, G. Doria, and R. Franco, "Gold-nanoparticle-probe-based assay for rapid and direct detection of Mycobacterium tuberculosis DNA in clinical samples," Clinical Chemistry, vol. 52, no. 7, pp. 1433-1434, 2006.

[14] E. D. Chan, R. Reves, J. T. Belisle, P. J. Brennan, and W. E. Hahn, "Diagnosis of tuberculosis by a visually detectable immunoassay for lipoarabinomannan," American Journal of Respiratory and Critical Care Medicine, vol. 161, no. 5, pp. 17131719, 2000.

[15] M. Pai, S. Kalantri, and K. Dheda, "New tools and emerging technologies for the diagnosis of tuberculosis: part II: active tuberculosis and drug resistance," Expert Review of Molecular Diagnostics, vol. 6, no. 3, pp. 423-432, 2006.

[16] W. H. Tan, K. Wang, X. He, et al., "Bionanotechnology based on silica nanoparticles," Medical Research Reviews, vol. 24, no. 5, pp. 621-638, 2004. 
[17] G. Yao, L. Wang, Y. R. Wu, et al., "FloDots: luminescent nanoparticles," Analytical and Bioanalytical Chemistry, vol. 385, no. 3, pp. 518-524, 2006.

[18] S. Santra, K. M. Wang, R. Tapec, and W. H. Tan, “Development of novel dye-doped silica nanoparticles for biomarker application," Journal of Biomedical Optics, vol. 6, no. 2, pp. 160-166, 2001.

[19] X. J. Zhao, R. Tapec-Dytioco, and W. H. Tan, "Ultrasensitive DNA detection using highly fluorescent bioconjugated nanoparticles," Journal of the American Chemical Society, vol. 125, no. 38, pp. 11474-11475, 2003.

[20] X. X. He, J. Y. Chen, K. M. Wang, W. H. Tan, and D. L. Qin, "Preparation and properties of $\mathrm{Cy} 3$ doped core-shell silica fluorescent nanoparticals," Chemical Journal of Chinese Universities, vol. 27, no. 10, pp. 1835-1839, 2006.

[21] S. Santra, P. Zhang, K. M. Wang, R. Tapec, and W. H. Tan, "Conjugation of biomolecules with luminophore-doped silica nanoparticles for photostable biomarkers," Analytical Chemistry, vol. 73, no. 20, pp. 4988-4993, 2001.

[22] S. Santra, H. Yang, D. Dutta, et al., "TAT conjugated, FITC doped silica nanoparticles for bioimaging applications," Chemical Communications, no. 24, pp. 2810-2811, 2004.

[23] S. Santra, B. Liesenfeld, D. Dutta, et al., "Folate conjugated fluorescent silica nanoparticles for labeling neoplastic cells," Journal of Nanoscience and Nanotechnology, vol. 5, no. 6, pp. 899904, 2005.

[24] J. K. Herr, J. E. Smith, C. D. Medley, D. H. Shangguan, and W. H. Tan, "Aptamer-conjugated nanoparticles for selective collection and detection of cancer cells," Analytical Chemistry, vol. 78, no. 9, pp. 2918-2924, 2006.

[25] X. J. Zhao, L. R. Hilliard, S. J. Mechery, et al., "A rapid bioassay for single bacterial cell quantitation using bioconjugated nanoparticles," Proceedings of the National Academy of Sciences of the United States of America, vol. 101, no. 42, pp. 1502715032, 2004.

[26] L. S. Schlesinger, C. G. Bellinger-Kawahara, N. R. Payne, and M. A. Horwitz, "Phagocytosis of Mycobacterium tuberculosis is mediated by human monocyte complement receptors and complement component C3," Journal of Immunology, vol. 144, no. 7, pp. 2771-2780, 1990.

[27] H. M. Cao, Handbook of Inorganic Compound Synthesis, vol. 1, Chemical Industry Publishing House, Beijing, China, 1988, (ed. Japanese Society of Chemistry) (in Chinese).

[28] M. M. Bradford, "A rapid and sensitive method for the quantitation of microgram quantities of protein utilizing the principle of protein dye binding," Analytical Biochemistry, vol. 72, no. 1-2, pp. 248-254, 1976.

[29] H. Yavuz and A. Denizli, "Immunoadsorption of cholesterol on protein A oriented beads," Macromolecular Bioscience, vol. 5, no. 1, pp. 39-48, 2005.

[30] B. Lu, M. R. Smyth, and R. O’Kennedy, “Oriented immobilization of antibodies and its applications in immunoassays and immunosensors," Analyst, vol. 121, no. 3, pp. 29R-32R, 1996.

[31] J. J. Langone, "Applications of immobilized protein A in immunochemical techniques," Journal of Immunological Methods, vol. 55, no. 3, pp. 277-296, 1982.

[32] V. S. Prisyazhnoy, M. Fusek, and Y. B. Alakhov, "Synthesis of high-capacity immunoaffinity sorbents with oriented immobilized immunoglobulins or their Fab' fragments for isolation of proteins," Journal of Chromatography, vol. 424, no. 2, pp. 243-253, 1988.
[33] X. L. Su and Y. Li, "Quantum dot biolabeling coupled with immunomagnetic separation for detection of Escherichia coli O157:H7," Analytical Chemistry, vol. 76, no. 16, pp. 48064810, 2004.

[34] M. Graille, E. A. Stura, A. L. Corper, et al., "Crystal structure of a Staphylococcus aureus protein domain complexed with the Fab fragment of a human IgM antibody: structural basis for recognition of B-cell receptors and superantigen activity," Proceedings of the National Academy of Sciences of the United States of America, vol. 97, no. 10, pp. 5399-5404, 2000.

[35] F. Reynolds, T. O’Loughlin, R. Weissleder, and L. Josephson, "Method of determining nanoparticle core weight," Analytical Chemistry, vol. 77, no. 3, pp. 814-817, 2005. 

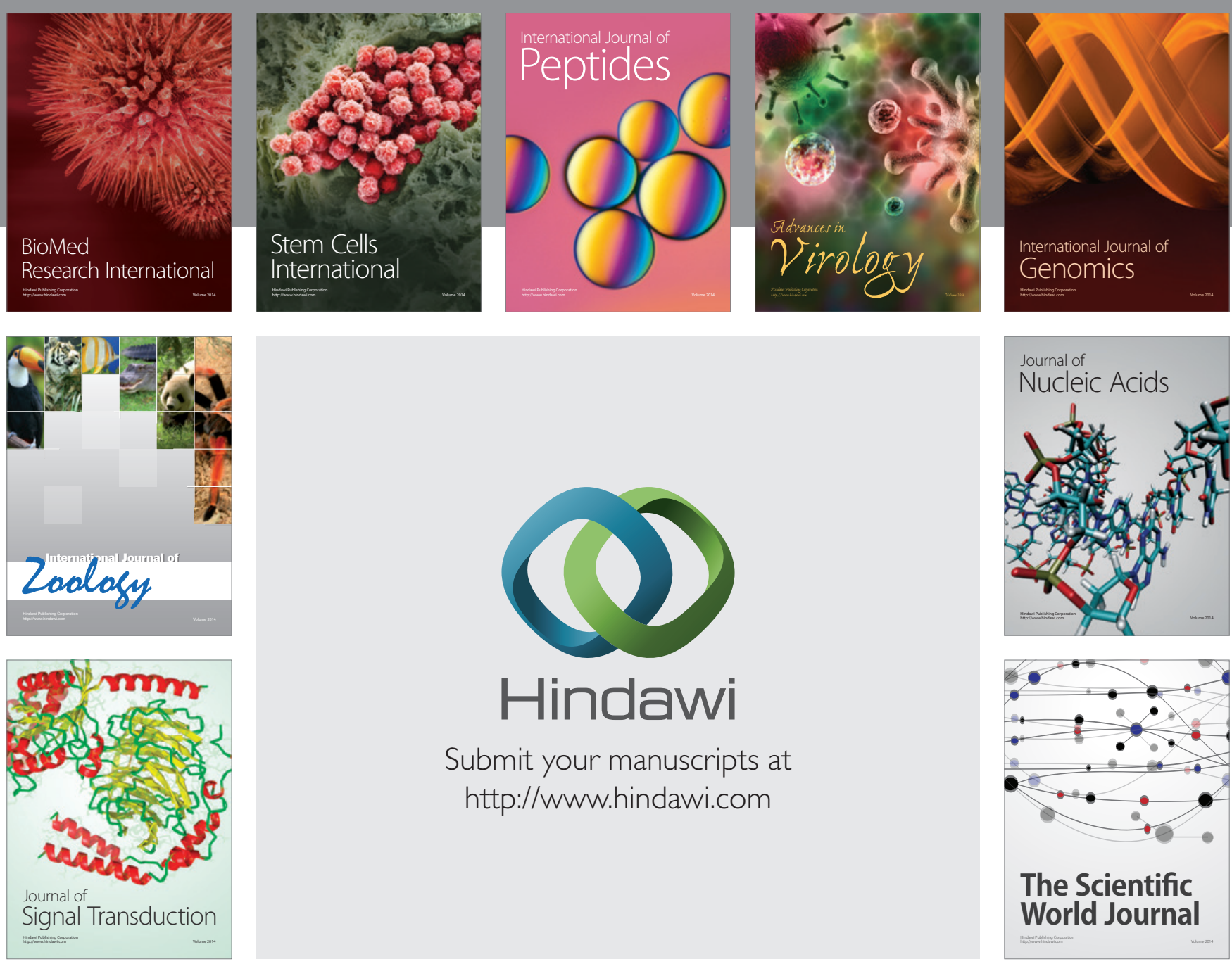

Submit your manuscripts at

http://www.hindawi.com
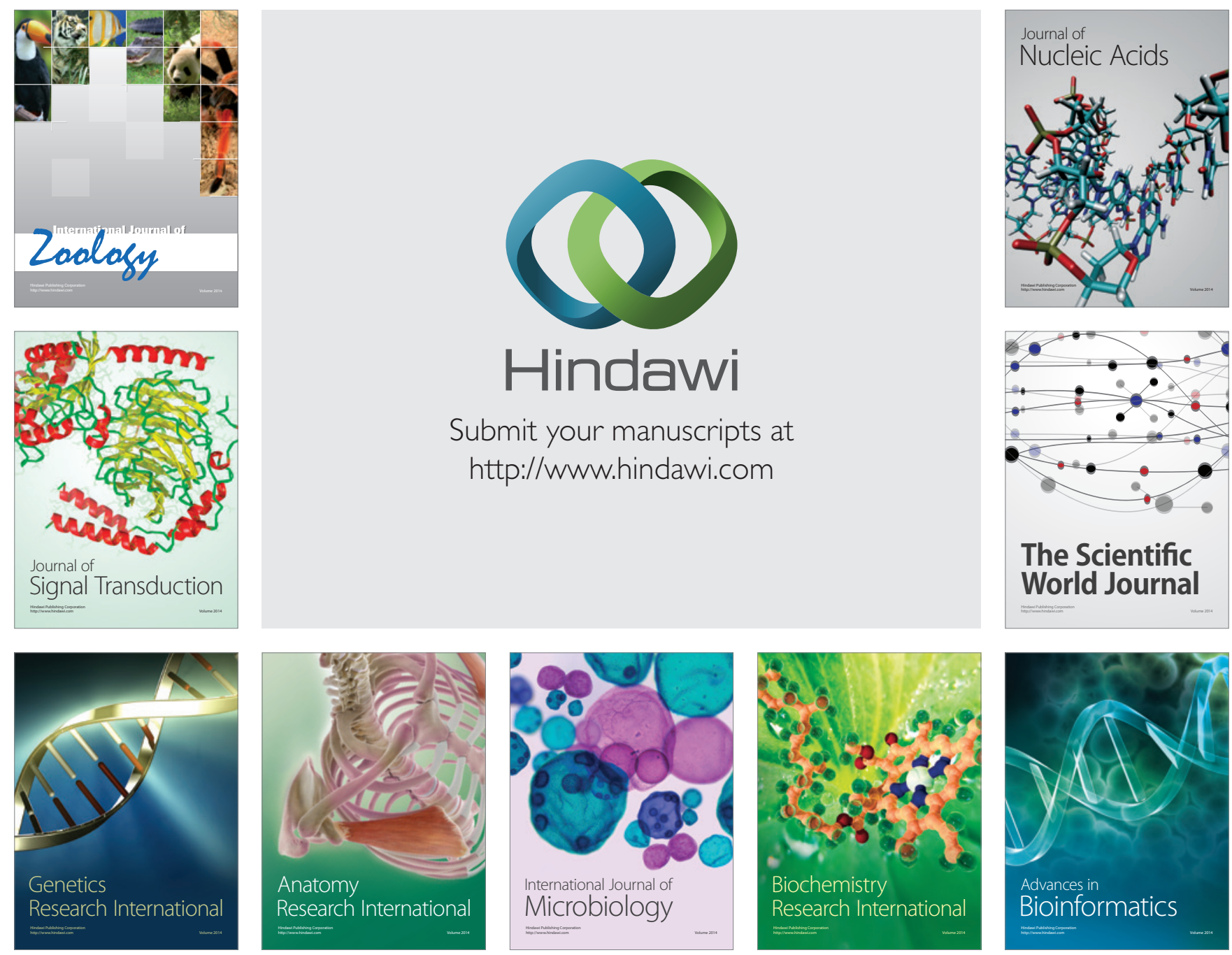

The Scientific World Journal
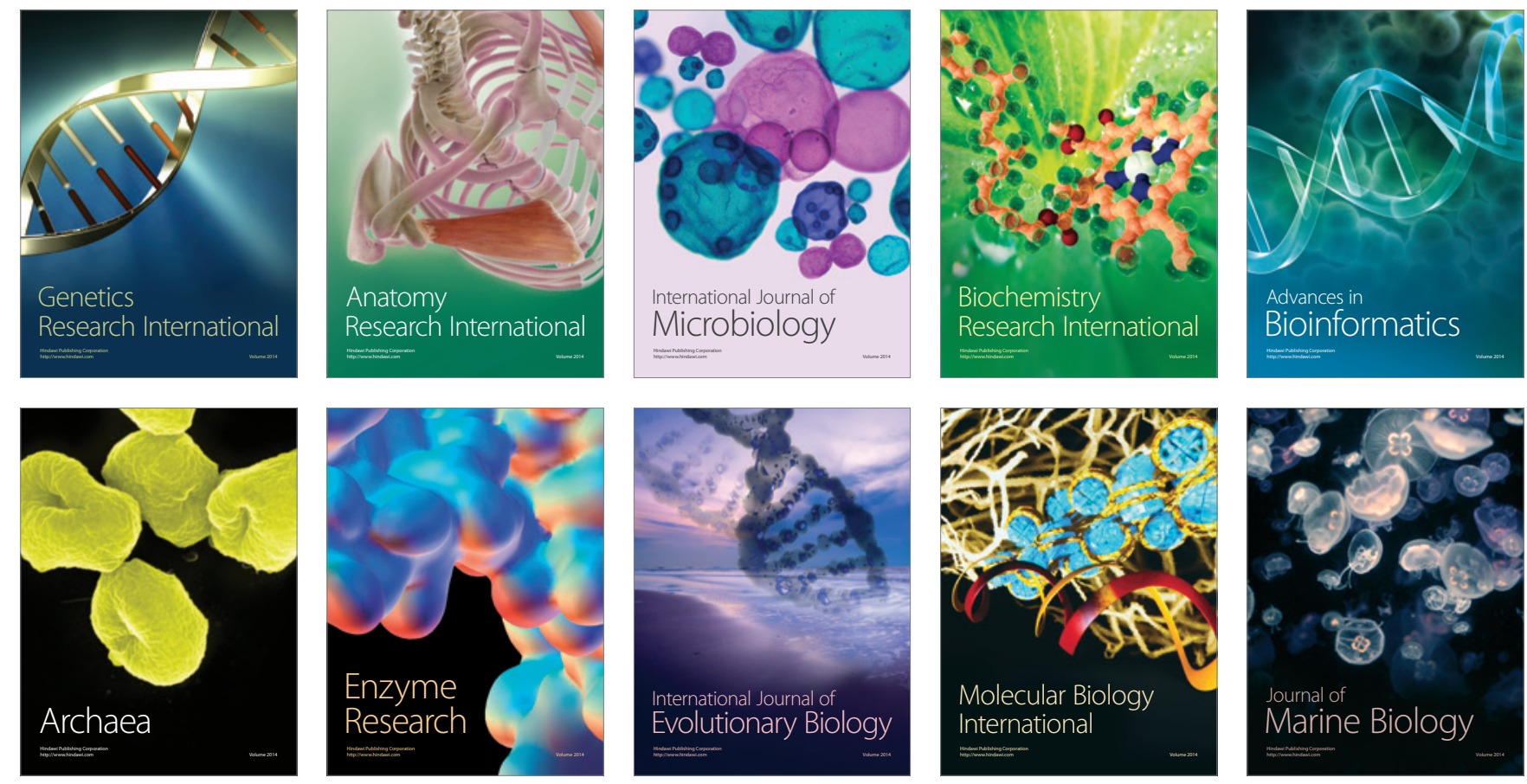